Article

\title{
Analytical Assessment for System Peak Reduction by Demand Responsive Resources Considering Their Operational Constraints in Wholesale Electricity Market
}

\author{
Seungmi Lee and Jinho Kim* \\ GIST Institute of Integrated Technology, Gwangju Institute of Science and Technology, Gwangju 61005, Korea; \\ smlee6842@gist.ac.kr \\ * Correspondence: jeikim@gist.ac.kr; Tel.: +82-62-715-5322
}

Received: 31 October 2018; Accepted: 28 November 2018; Published: 30 November 2018

\begin{abstract}
It has been four years since the introduction of the Demand Response (DR) market in Korea. Although the DR market has been steadily increasing resource capacity and payments for demand resources, it cannot efficiently utilize DR resources under the current domestic policy system. In addition, research on the level at which the demand resource capacity registered in the DR market contributes to the reduction of peak demand is scarce. In this article, an algorithm that calculates the annual peak demand reduction contribution is developed considering the operational characteristics of DR resources in order to utilize the demand resources at a meaningful level. Also the peak demand reduction contribution is simulated for the next 15 years based on the historical electricity demand pattern in Korea and analyze the sensitivity of policy variables that affect the contribution of peak reduction. Finally, the critical policy constraint that affects the contribution of DR resources is identified and a method is proposed to improve the peak reduction contribution of DR resources. Related departments that operate the demand market can use this research as a reference for market operations.
\end{abstract}

Keywords: Demand Response (DR); market simulation; Mixed Integer Linear Program (MILP); peak reduction contribution; policy sensitivity analysis

\section{Introduction}

Demand Response (DR) resources are recognized globally as eco-friendly resources that increase the operational efficiency of an electrical power system by reducing peak demand and power generation costs [1,2]. A DR market is a system in which electricity users sell power to the electricity market in a way that reduces power usage, e.g., when the market price of electricity is high, or the power system is in crisis [3]. Demand Response resources have great potential in meeting the increasing demand for electricity. Various studies have verified the significance and effectiveness of DR resources and with increasing global attention, the implementation of DR resources is diversifying [4-10].

According to the report of the Korea Energy Economics Institute, the results of analysis of the DR market operation performance show that although the performance has been increasing since the opening of the market, it is necessary to improve the system in order to activate the market [4]. DR can be combined with Unit Commitment (UC) to benefit for both Generating Companies (GENCOs) and customers [5], and the framework was analyzed for integrating DR into long-term resource planning [6]. In addition, DR methods have been studied in connection with other distributed resources such as PHEV, wind power, etc. [7] or other various studies such as economics can be combined with DR to study incentives and penalties based on [8] or consumer behavior $[9,10]$. 
Utilizing DR resources can have various purposes [1]; this paper focuses on the ability of DR resources to reduce or alleviate peak demand. Peak demand management is crucial in maintaining capacity reserves and reasonable energy prices. In particular, countries that experience demand patterns with high load rates, such as developed countries, can expect remarkable performance regarding peak shaving [11,12].

The DR market was introduced in 2014 in Korea. It has since continued to grow, with 43 DR service providers (DRSPs) registered in the Korea Power Exchange (KPX) and 2273 customers participating in the DR market. The DR resources steadily increased from 1520 megawatt hour (MW) in 2014, to $4151 \mathrm{MW}$ in June 2018, equivalent to four nuclear power plants. Cumulative electricity reduction is about 899 gigawatt hour (GWh), with annual average power savings of $274.8 \mathrm{GWh}$, and the total settlement by the KPX is about $\$ 455.47$ million (USD) by utilizing DR resources (As of April 2018) [13].

Despite steadily increasing in resource capacity and payments for demand resources [13], the DR market cannot efficiently utilize DR resources under the current domestic policy. In addition, few studies analyze the level at which the demand resource capacity in the DR market contributes to the reduction of peak demand. Thus, there are several limitations in establishing an efficient, long-term resource plan and operating the market using DR resources [6,14]. Simply, it can be assumed that all the DR resource capacity in the DR market contributes to the reduction of peak demand. However, DR resources have various operational constraints that are distinct from conventional power generation resources, and in extreme cases, they may not contribute to peak demand reduction at all.

There are various studies related to DR resources; some provide overviews of existing DR programs and their benefits, costs [1,15-18], and challenges [19-22]. O'Connell discusses several challenges to overcome before DR resources can offer a valuable contribution to the power system. While DR resources can bring many benefits, the author notes that the most important problem is the lack of experience with and understanding of the nature of DR resources [19]. Nolan presents some key barriers to deployment, challenges in the evaluation of demand response, and provides some recommendations on evaluation methodologies [21]. Satchwell explains the increasing involvement of DR resources in resource planning and analyzes the current framework for integrating long-term resource planning, presenting various approaches [6]. Kim explains that DR programs often fail to achieve their goals and reach their potential, reviews the key structural and behavioral barriers, and proposes solutions for DR programs [23]. In Florida, Stoll analyzes the impact on grid operations of various load types that provide demand response to quantify the potential impact of demand response [24].

Kwag proposes optimal combined scheduling with DR by minimizing the system operation cost and develops the marginal cost function of the demand resource [25]. Zhou develops a general framework that models and analyzes the operational flexibility parameters and constraints of DR and Energy Storage System (EES) to evaluate if they can adequately contribute to supply [26]. Li proposed distributed algorithms for a utility company and consumers to optimize their benefits and maximize social welfare [2]. Keane develops models of DR on the Irish power system and demonstrates that DR can contribute to overall system adequacy and displace conventional generation [27]. However, many studies lack a general evaluation of the effectiveness of DR resources. In particular, few studies analyze the system effects, including the characteristics of DR resources and policy.

In this study, an algorithm that can calculate the annual peak demand reduction contribution is developed considering the operational characteristics of DR resources, so that the demand resources can be utilized at a meaningful level. Also the peak demand reduction contribution is simulated for the next 15 years based on the historical electricity demand pattern in Korea. In addition, the sensitivity of policy variables that affect peak reduction is analyzed and a method is proposed to improve the peak reduction contribution of DR resources. 


\section{Mathematical Problem Formulation}

The algorithm in this study finds the DR Dispatch Commitment Quantity (DCQ) for each DR resource that minimizes the annual peak load after DR events. This enables us to optimally reduce the annual peak demand and obtain a solution that effectively allocates and manages DR resources. The objective function of the optimization problem minimizes the annual peak load after a DR dispatch, and it is calculated by considering the operational constraints of DR resources in the Korean electricity market. To solve it efficiently, the problem has been formulated through Mixed Integer Linear Programming (MILP).

\subsection{Objective Function}

The objective function minimizes the annual peak load after a DR event. The annual peak load after the DR event is the largest value of the demand and is calculated by subtracting the DR DCQ from the electricity demand for each time period. Demand response DCQ is the amount of reduced electricity usage directed by the DR dispatching instruction. During the DR event, the DR DCQ of each DR resource is calculated as the sum of the individual DR reductions. If an optimal solution is found by verifying unavailable DR resources that are in violation of DR operational constraints and adjusting the timing of DR dispatching, or allocating DR resources appropriately, the annual peak reduction effect can be maximized.

The equation is expressed as follows.

$$
\begin{gathered}
\min _{D R(i, t)}[\max \{\text { demand }(t)-D R(t)\}] \\
D R(t)=\sum_{i \in I} D R(i, t)
\end{gathered}
$$

where demand $(t)$ is electricity demand and $D R(t)$ denotes DR Dispatch Commitment Quantity (DCQ) at time $t$. $D R(t)$ is calculated as the sum of the $D R(i, t)$ which is the DR DCQ of the $i$-th resource at time $t$ where $I$ is a set of DR resources.

\subsection{Operational Constraints}

To estimate more accurate peak reduction effects of DR, it is necessary to comply with the operating constraints of the DR market. This study considers the following four constraints.

First, the time allowed for annual DR dispatch for each DR resource is limited to $60 \mathrm{~h}$. Second, the DR dispatch can occur between 09:00 and 20:00 on weekdays and does not occur at 13:00. Third, DR resources participating in a DR event must maintain a reduction for at least one hour after the start of demand reduction and can maintain the reduction until a maximum of four hours. Finally, the number of requests for a DR event in a day for each DR resource is limited to two.

\subsubsection{Maximum Dispatch Duration (per Year)}

The total participation time for reduction during the electricity trading period (typically one year) is less than $Y_{-} M A X$ hours per year.

$$
Y \operatorname{Count}(i)=\sum_{t=1}^{T}[D R(i, t) \times \operatorname{onoff}(i, t)]
$$

where $Y \operatorname{Count}(i)$ is the annual cumulative participation time of the $i$-th resource in the DR event and it is calculated by onoff $f(i, t)$ which denotes a DR event participation state indicator for $i$-th DR resource at time $t$ ( 1 denotes participation and 0 denotes non-participation). $Y_{-} M A X$ is the maximum time available that a resource can participate in the DR event for one year and $Y$ Count $(i)$ is limited as:

$$
0 \leq Y \text { Count }(i) \leq Y \_M A X
$$




\subsubsection{Dispatchable Time}

A DR event occurs between 09:00 and 20:00 and excludes 13:00. The remaining time is called non-dispatchable, and demand is assumed as zero at that time.

$$
\begin{gathered}
D R\left(t_{o f f}\right)=0 \\
t_{o f f} \in T_{o f f}
\end{gathered}
$$

where $t_{o f f}$ is non-dispatchable time and $T_{\text {off }}$ is the set of non-dispatchable time such as $1,2, \ldots, 9,13$, $21, \ldots, 23,24$.

\subsubsection{Sustained Response Period (per Event)}

DR resources participating in a DR event must sustain a reduction for at least $D \_M I N$ hours after the start of demand reduction and can maintain the reduction for a maximum of $D \_M A X$ hours. When the DR event is dispatched and the DR resource starts to reduce demand, it can be determined whether reduction should continue in the next time period, depending on the preceding reduction time and duration.

According to market regulations, the duration of the DR event must satisfy the minimum Sustained Response Period (SRP) and the maximum holding SRP. Under the current market regulations in Korea, the duration of a DR event is at least $1 \mathrm{~h}$, and the maximum holding time is $4 \mathrm{~h}$.

$$
\begin{gathered}
{\left[\operatorname{Dur}(i, t-1)-D \_M I N\right] \times[\operatorname{onoff}(i, t-1)-\operatorname{onoff}(i, t)] \geq 0} \\
\operatorname{Dur}(i, t)=[\operatorname{Dur}(i, t-1)+1] \times \operatorname{onoff}(i, t) \\
\text { D_MIN } \leq \operatorname{Dur}(i, t) \leq D \_M A X
\end{gathered}
$$

where $\operatorname{Dur}(i, t)$ denotes the duration of $i$-th DR resource at time $t$ during a DR event. $\operatorname{Dur}(i, t)$ is determined between $D_{-} M I N$ and D_MAX, which denotes the minimum SRP and the maximum SRP, respectively.

\subsubsection{Available Number of Dispatches (per Day)}

Demand reduction requests for DR resources are limited to $F_{-} M A X$ times a day. Variables on $(t)$ and off $(t)$ is added that indicate the participation state of the DR resource and, based on these variables, it verifies whether the proposed DR dispatch satisfies the participation constraint for the day.

$$
\begin{gathered}
\text { on }(i, t)-\operatorname{off}(i, t)=\operatorname{onoff}(i, t)-\operatorname{onoff}(i, t-1) \\
\text { on }(i, t)+\operatorname{off}(i, t) \leq 1 \\
\text { Freq }(i, d)=\sum_{t \in T_{\text {on }}} \text { on }(i, t), d \in D \\
\text { Freq }(i, d) \leq F_{-} M A X
\end{gathered}
$$

where on $(i, t)$ is equal to 1 if the $i$-th DR resource changed from non-participation to participation at time $t$ and 0 otherwise. On the contrary, off $(i, t)$ is equal to 1 if the $i$-th DR resource changed from participation to non-participation at time $t$ and 0 otherwise. Freq $(i, d)$ in Equation (12) denotes the number of times the $i$-th DR resource has participated in a DR event on day $d$. Freq $(i, d)$ is limited by $F \_M A X$ which denotes the maximum available number of DR dispatches in a day. 


\section{Case Study of the Korean DR Market}

In this section, the simulation is conducted to estimate the peak reduction contribution of DR resources and considered DR market operating constraints in order to derive a more accurate reduction effect in the Korean electricity market. In addition, sensitivity analysis is conducted for each constraint to find factors inhibiting the reduction effects of the current DR market system and improvement ways are suggested.

One important factor determining annual peak demand is the electricity demand pattern for that year. Summing up real-time electricity use reveals a demand pattern, which has a certain shape or characteristic, in a specific time period (e.g., day, month, year, and so on). These patterns of electricity demand differ every year, as they are subject to various environmental impacts. The patterns of electric power demand on weekdays and weekends are different, and there is significant difference in electricity use between daytime and nighttime.

Since the annual peak is determined at the time of highest demand in the year, it is necessary to manage DR resources appropriately, according to DR market regulations, to reduce annual peak demand effectively. However, owing to operational restrictions on DR resources in the Korean DR market, it is important to understand the electricity load pattern to maximize the peak reduction effect, while complying with regulations.

Consequently, Korea has exhibited widely varying patterns of electricity demand in 2014-2016, which is substantiated by the peak reduction simulation results. To improve the reliability of the simulation, the patterns are analyzed for the past three years, perform the simulation for each year, and discuss the results below.

\subsection{Simulation Overview}

The estimated annual peak reduction contribution was obtained in the General Algebraic Modeling System (GAMS) environment and solved by CPLEX, which can solve MILP effectively [28]. The formulation was applied to simulate the Korean electricity market, and the basic data set for the simulation was from the real power system.

\subsubsection{Input Data and Assumptions}

The data set used in this paper is from the Korea Electric Power Corporation (KEPCO), and the data produced for the simulation are based on the 8th Basic Plan for Long-term Electricity Supply and Demand (BPE) from Korea Power Exchange (KPX) [29]. The BPE is published biennially, and the 8th BPE from the end of 2017, addresses the 2017-2031 period.

\section{Electricity load}

In the simulation, the future electricity demand patterns for 15 years (2017-2031) are forecasted based on the power generator performance data (demand before DR event) for each hour from 2014 to 2016. As prediction is beyond the main research purpose of this study, the future electricity demand assumed in a simple method without using complex formulas or regression analysis. The method of predicting future electricity demand patterns is based on the 8th BPE demand side management plan, and electricity load patterns are forecasted to meet the annual peak demand and power consumption. More specifically, after setting the peak demand of the forecast year to be equal to the annual peak demand of the 8th BPE, the electricity demand adjusted for the remaining time zones according to the year pattern of the three simulations (2014 to 2016). At this time, the electricity demand is proportionally increased, and the sum of all annual electricity demand per year is set equal to the forecasted power consumption of the 8th BPE before demand management. The annual peak demand and power consumption forecasted by the 8th BPE are shown in Table 1 below. 
Table 1. Target Demand Outlook DR by the 8th BPE.

\begin{tabular}{cccccccc}
\hline Year & $\mathbf{2 0 1 8}$ & $\mathbf{2 0 1 9}$ & $\mathbf{2 0 2 0}$ & $\mathbf{2 0 2 1}$ & $\mathbf{2 0 2 2}$ & $\mathbf{2 0 2 3}$ & $\mathbf{2 0 2 4}$ \\
\hline $\begin{array}{c}\text { Peak demand (MW) } \\
\text { Power consumption (GWh) }\end{array}$ & $\mathbf{8 8 , 9 0 7}$ & 91,262 & 93,594 & 95,991 & 98,148 & 100,251 & 102,325 \\
\hline Year & $\mathbf{2 0 2 5}$ & $\mathbf{2 0 2 6}$ & $\mathbf{2 0 2 7}$ & $\mathbf{2 0 2 8}$ & $\mathbf{2 0 2 9}$ & $\mathbf{2 0 3 0}$ & $\mathbf{2 0 3 1}$ \\
\hline Peak demand (MW) & 104,369 & 106,342 & 108,241 & 110,023 & 111,759 & 113,407 & 114,922 \\
Power consumption (GWh) & 615,788 & 627,064 & 637,866 & 647,946 & 657,725 & 666,955 & 675,367 \\
\hline
\end{tabular}

\section{Demand Response Resources}

The total registered capacity of DR resources is based on a total of 4352 MW (62 units), including 467 MW of new DR resources registered in May 2017, and the total registered capacity of DR resources for the next 15 years is assumed.

Considering that DR resource registration capacity is increasing and future DR resource recruitment will be extended to small-scale customers such as commercial buildings, DR resource registration capacity for the next 15 years is set to gradually increase, corresponding to $5 \%$ of the expected peak demand (MW) for each year. Table 2 below shows the DR resource registered capacity per year.

Table 2. DR resource registration capacity per year (assumption).

\begin{tabular}{cccccccc}
\hline Year & $\mathbf{2 0 1 8}$ & $\mathbf{2 0 1 9}$ & $\mathbf{2 0 2 0}$ & $\mathbf{2 0 2 1}$ & $\mathbf{2 0 2 2}$ & $\mathbf{2 0 2 3}$ & $\mathbf{2 0 2 4}$ \\
\hline Registered Capacity (MW) & 4445 & 4563 & 4680 & 4800 & 4907 & 5013 & 5116 \\
Number of DR resources & 62 & 63 & 63 & 64 & 65 & 70 & 75 \\
\hline Year & $\mathbf{2 0 2 5}$ & $\mathbf{2 0 2 6}$ & $\mathbf{2 0 2 7}$ & $\mathbf{2 0 2 8}$ & $\mathbf{2 0 2 9}$ & $\mathbf{2 0 3 0}$ & $\mathbf{2 0 3 1}$ \\
\hline Registered Capacity (MW) & 5218 & 5317 & 5412 & 5501 & 5588 & 5670 & 5746 \\
Number of DR resources & 80 & 85 & 90 & 95 & 100 & 105 & 110 \\
\hline
\end{tabular}

\subsubsection{Simulation Design}

This simulation calculates the annual peak contribution effect based on the 15-year future demand pattern estimated in Section 3.1.1 and compliance with current market rules. This result is considered a reference case for analyzing the sensitivity of each constraint. Sensitivity analysis for each constraint is conducted by setting four policy constraints that affect the peak reduction effect as variables and adjusting the condition range incrementally. Each result is compared with the reference case and the difference is quantitatively analyzed.

The sensitivity analysis is carried out in two stages. The initial stage measures and compares the results of the simulations by changing the conditions of each variable (by strengthening or mitigating one step). It is implemented as a one-step strengthening adjustment and a one-step relaxing adjustment for each policy variable. Although the adjustment method for each variable is slightly different, basically each level adjustment is determined in integer units.

The "Maximum Dispatch Duration" variable is set at 30 and $70 \mathrm{~h}$ to examine a level at which a meaningful change was observed. The "Dispatchable Time" variable is set to shift the entire time zone without changing the total time available. The time zone is 08:00 to 19:00 and 10:00 to 21:00 for each.

Since the condition of each variable is not a parallel relation, it is difficult to compare directly. For example, "Maximum Dispatch Duration" is a constraint that determines the total amount of time that a DR resource may participate in DR events annually. Therefore, the condition must be adjusted in units of time such as 60 and $50 \mathrm{~h}$. On the other hand, since the "Dispatchable Time" constraint is a condition that adjusts the time slot to perform the task, it is necessary to adjust the time zone, such as from 9:00 to 20:00, in which the DR event can occur. 
Therefore, in this paper, a more detailed sensitivity analysis was performed considering the characteristics of each constraint. All possible conditions for the policy variable are assigned a range of integer values. Simulation results in which meaningful changes are detected in all cases are selected and included.

The condition cases for each policy variable were classified as follows Table 3.

Table 3. The condition cases of each policy variable for sensitivity analysis.

\begin{tabular}{|c|c|c|c|c|c|c|}
\hline Policy Variable & \multirow{2}{*}{$\begin{array}{c}\text { Reference } \\
60 \mathrm{H}\end{array}$} & \multicolumn{4}{|c|}{ Condition Cases } & \multirow{2}{*}{ Abbreviation } \\
\hline \multirow{2}{*}{$\begin{array}{l}\text { Maximum Dispatch Duration } \\
\text { Dispatchable Time }\end{array}$} & & $20 \mathrm{H}$ & $40 \mathrm{H}$ & $50 \mathrm{H}$ & $80 \mathrm{H}$ & \\
\hline & 09:00-20:00 & 08:00-21:00 & 07:00-22:00 & 10:00-19:00 & $11: 00-18: 00$ & Time \\
\hline Sustained Response Period & 1 to 4 /event & 1 to 2 & 1 to 3 & 1 to 5 & 1 to 6 & Duration \\
\hline Available Number of Dispatch & 2/day & $1 / \mathrm{da}$ & & 3/day & & Frequency \\
\hline
\end{tabular}

For simplicity, abbreviations of the policy constraints in Table 3 are used.

\subsection{Simulation Results}

An analysis of power demand patterns for the past three years (2014-2016) shows that each yearly pattern has significantly different characteristics, and simulation results suggest that the determinants affecting the annual peaks are different. In this section, annual peak demand in each year is examined in detail based on the reference case to estimate the annual peak reduction effect and to identify the determining factors.

In 2016, the demand for electricity for $7 \mathrm{~h}$ on August 12 was within the highest 60th for the year. In general, it is possible that the DR resource participates in the DR event two times for four hours a day, up to $8 \mathrm{~h}$, but this is virtually impossible because DR resources could not participate at 13:00. Therefore, due to the lack of participation in some time periods on August 12, the annual peak demand will be determined from among the seven hours, which is the 17th time zone demand with the lowest power demand in that day. Demand at that time can be determined as the annual power peak if there is no higher demand than the 17th for a situation that violates constraints.

In 2015, the time slot with the 76th highest annual power demand was 08:00-09:00, which is outside DR dispatchable time. Therefore, if there is no higher demand than this after the DR event in the same year, the DR demand is not determined by the DR event and this could be the annual peak demand since the DR resource was not utilized at that time.

There was high demand for electricity in 2014 between 08:00 and 09:00 (which is outside of DR dispatchable time), mainly due to morning demand. The 29th highest annual electricity demand occurred between 08:00 and 09:00, and demand reduction cannot be requested in this period despite the high demand because the DR event does not work; therefore, it can be determined as the annual peak demand.

Because the peak determining factors are different according to the demand pattern for each year, there are slight differences in the results. The peak reduction contribution reduces demand by $3.65-4.8 \%$ of the annual peak demand. The simulation results for the three years are summarized in Table 4, which is the reference case for the sensitivity analysis.

Based on these simulation results, the initial sensitivity of each constraint is analyzed by simulation, and a different setting range is applied to each constraint condition according to its characteristics. The results are shown in Tables 5 and 6 . Sensitivity simulations for relaxed constraints were set by adjusting the condition of each constraint and assuming that the DR resource would more readily participate in DR events. In contrast, the sensitivity simulation results for strengthened constraints were designed to hinder the participation of DR resources in DR events by adjusting the time period or the limiting participation time of each constraint. 
Table 4. Summary of reference case simulation results (2014-2016 LDC).

\begin{tabular}{|c|c|c|c|c|c|c|c|c|}
\hline \multirow[b]{2}{*}{ Year } & \multirow{2}{*}{$\begin{array}{c}\text { Capacity } \\
\text { (MW) }\end{array}$} & \multirow{2}{*}{$\begin{array}{l}\text { Peak Demand } \\
\text { (MW) }\end{array}$} & \multicolumn{2}{|c|}{2016 LDC } & \multicolumn{2}{|c|}{2015 LDC } & \multicolumn{2}{|c|}{2014 LDC } \\
\hline & & & $\begin{array}{l}\text { Reduction } \\
\text { (MW) }\end{array}$ & $\begin{array}{c}\text { Contribution } \\
(\%)\end{array}$ & $\begin{array}{l}\text { Reduction } \\
\text { (MW) }\end{array}$ & $\begin{array}{c}\text { Contribution } \\
(\%)\end{array}$ & $\begin{array}{l}\text { Reduction } \\
\text { (MW) }\end{array}$ & $\begin{array}{c}\text { Contribution } \\
(\%)\end{array}$ \\
\hline 2017 & 4352 & 86,546 & 4177 & $4.83 \%$ & 3848 & $4.45 \%$ & 3155 & $3.65 \%$ \\
\hline 2018 & 4445 & 88,907 & 4270 & $4.80 \%$ & 3953 & $4.45 \%$ & 3241 & $3.65 \%$ \\
\hline 2019 & 4563 & 91,262 & 4384 & $4.80 \%$ & 4058 & $4.45 \%$ & 3327 & $3.65 \%$ \\
\hline 2020 & 4680 & 93,594 & 4497 & $4.80 \%$ & 4161 & $4.45 \%$ & 3412 & $3.65 \%$ \\
\hline 2021 & 4800 & 95,991 & 4612 & $4.80 \%$ & 4268 & $4.45 \%$ & 3499 & $3.65 \%$ \\
\hline 2022 & 4907 & 98,148 & 4714 & $4.80 \%$ & 4364 & $4.45 \%$ & 3578 & $3.65 \%$ \\
\hline 2023 & 5013 & 100,251 & 4816 & $4.80 \%$ & 4457 & $4.45 \%$ & 3655 & $3.65 \%$ \\
\hline 2024 & 5116 & 102,325 & 4909 & $4.80 \%$ & 4549 & $4.45 \%$ & 3730 & $3.65 \%$ \\
\hline 2025 & 5218 & 104,369 & 5006 & $4.80 \%$ & 4640 & $4.45 \%$ & 3805 & $3.65 \%$ \\
\hline 2026 & 5317 & 106,342 & 5109 & $4.80 \%$ & 4728 & $4.45 \%$ & 3877 & $3.65 \%$ \\
\hline 2027 & 5412 & 108,241 & 5199 & $4.80 \%$ & 4812 & $4.45 \%$ & 3946 & $3.65 \%$ \\
\hline 2028 & 5501 & 110,023 & 5277 & $4.80 \%$ & 4892 & $4.45 \%$ & 4011 & $3.65 \%$ \\
\hline 2029 & 5588 & 111,759 & 5359 & $4.79 \%$ & 4969 & $4.45 \%$ & 4074 & $3.65 \%$ \\
\hline 2030 & 5670 & 113,407 & 5441 & $4.80 \%$ & 5042 & $4.45 \%$ & 4134 & $3.65 \%$ \\
\hline 2031 & 5746 & 114,922 & 5517 & $4.80 \%$ & 5109 & $4.45 \%$ & 4189 & $3.65 \%$ \\
\hline
\end{tabular}

The average contribution, shown in Tables 5 and 6 below, refers to the peak reduction effect from DR events on average from 2017 to 2031. It shows how much peak demand is reduced compared to before the DR event. Increased contribution implies an increased peak reduction contribution by alleviating the condition of each constraint, and increased reduction indicates how much the overall peak demand reduction has increased as the contribution increases. On the contrary, decreased contribution and decreased reduction mean a decreased peak reduction contribution and rate of peak reduction when the constraints are strengthened.

In Tables 5 and 6, peak determinants are an indicator of which factors determine the annual peak in the simulation in terms of hours, time, duration, and frequency. Max is the case where the annual peak is reduced by maximizing the utilization of DR resources. On the other hand, Exh. is the case where all resources are exhausted due to a lack of DR resources, but the peak reduction effect is not as great as expected.

As a result of the simulation, if the constraint condition of each policy variable is marginally relaxed, no significant change compared to the existing reference case is observed. Nevertheless, when the conditions of variables such as "Time" and "Duration" are relaxed, power peaks can be maximally reduced by utilizing all the DR resources in some electricity demand patterns.

For example, in 2014, since there was high electricity demand at a time when a DR event could not occur, high demand was determined as an annual peak demand without using DR resources. In such a case, the peak reduction effect can be greatly improved even if only a slight adjustment of the time period in which the DR resource is available is possible. Simulation results show that the overall peak reduction effect has increased by about 1.36 percentage points, from $3.65 \%$ to $5 \%$. This number may seem small, but is actually an increase of more than $37 \%$ compared to the reference case demand reduction capacity. The capacity is about $1174 \mathrm{MWh}$ or more, which is equivalent to the capacity of one nuclear power plant.

Table 5. Summary of initial sensitivity simulation results with relaxed constraints.

\begin{tabular}{|c|c|c|c|c|c|c|c|c|c|c|c|c|}
\hline \multirow{2}{*}{$\begin{array}{l}\text { Policy Variable } \\
\text { LDC pattern }\end{array}$} & \multicolumn{3}{|c|}{ Hours } & \multicolumn{3}{|c|}{ Time } & \multicolumn{3}{|c|}{ Duration } & \multicolumn{3}{|c|}{ Frequency } \\
\hline & ‘16 & ‘ 15 & $' 14$ & $‘ 16$ & $' 15$ & $‘ 14$ & $‘ 16$ & $` 15$ & $' 14$ & ‘16 & $' 15$ & '14 \\
\hline Average Contribution (\%) & 4.80 & 4.45 & 3.65 & 4.80 & 5.00 & 5.00 & 5.00 & 4.45 & 3.65 & 4.80 & 4.45 & 3.65 \\
\hline Increased Contribution ( $\%$ ) & 0.00 & 0.00 & 0.00 & 0.00 & 0.56 & 1.36 & 0.20 & 0.00 & 0.00 & 0.00 & 0.00 & 0.00 \\
\hline Increased Reduction (\%) & 0.00 & 0.00 & 0.00 & 0.00 & 12.50 & 37.21 & 4.15 & 0.00 & 0.00 & 0.00 & 0.00 & 0.00 \\
\hline Peak Determinants & $\mathrm{D} / \mathrm{F}$ & $\mathrm{T}$ & $\mathrm{T}$ & $\mathrm{D} / \mathrm{F}$ & Max & Max & Max & $\mathrm{T}$ & $\mathrm{T}$ & $\mathrm{D} / \mathrm{F}$ & $\mathrm{T}$ & $\mathrm{T}$ \\
\hline
\end{tabular}


On the contrary, if the constraint condition of the policy variable is strengthened, the peak reduction effect is significantly reduced in most results for all variables. In particular, findings are that the effect is greatly reduced by adjusting the range of conditions for the "Time" variable, and the peak reduction effect appeared to be low in some cases.

For example, in the case of the electricity demand pattern in 2015, because the demand is concentrated in a specific period, even if the period for initiating the DR event is shifted by one hour, the condition becomes very severe and the peak reduction effect is greatly reduced. Simulation results show that the overall peak reduction effect is only $0.48 \%$, down 3.95 percentage points from $4.45 \%$, which is about $89 \%$ less than the reference case demand reduction capacity. When converted to capacity, it is equivalent to about $3429 \mathrm{MWh}$, or the capacity of three nuclear power plants.

Table 6. Summary of initial sensitivity simulation results with strengthened constraints.

\begin{tabular}{|c|c|c|c|c|c|c|c|c|c|c|c|c|}
\hline \multirow{2}{*}{$\begin{array}{l}\text { Policy Variable } \\
\text { LDC pattern }\end{array}$} & \multicolumn{3}{|c|}{ Hours } & \multicolumn{3}{|c|}{ Time } & \multicolumn{3}{|c|}{ Duration } & \multicolumn{3}{|c|}{ Frequency } \\
\hline & $‘ 16$ & $‘ 15$ & '14 & ‘16 & $‘ 15$ & ‘14 & '16 & $‘ 15$ & $' 14$ & ‘16 & ‘15 & ‘'14 \\
\hline Ave & 4.74 & 4.45 & 3.65 & 3.64 & 0.48 & 0.54 & 3.12 & 3.89 & 3.35 & 3.79 & 3.89 & 3.35 \\
\hline Decreased Contribution (\%) & 0.06 & 0.00 & 0.00 & 1.16 & 3.96 & 3.11 & 1.68 & 0.56 & 0.30 & 1.02 & 0.56 & 0.30 \\
\hline Decreased Reduction (\%) & 1.33 & 0.00 & 0.00 & 24.11 & 89.12 & 85.25 & 34.94 & 12.54 & 8.20 & 21.17 & 12.54 & 8.20 \\
\hline Peak Determinants & Exh. & $\mathrm{T}$ & $\mathrm{T}$ & $\mathrm{T}$ & $\mathrm{T}$ & $\mathrm{T}$ & $\mathrm{D} / \mathrm{F}$ & $\mathrm{D} / \mathrm{F}$ & $\mathrm{D} / \mathrm{F}$ & $\mathrm{D} / \mathrm{F}$ & $\mathrm{D} / \mathrm{F}$ & $\mathrm{D} / \mathrm{F}$ \\
\hline
\end{tabular}

Figure 1 graphically shows the average contribution when each constraint is strengthened or relaxed.

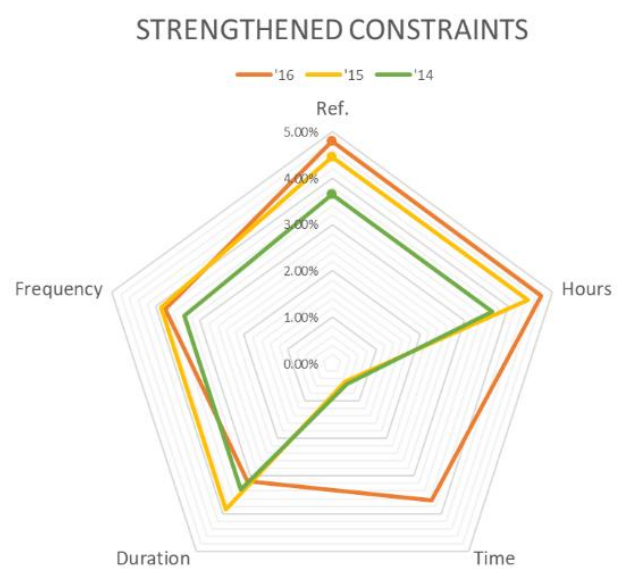

(a)

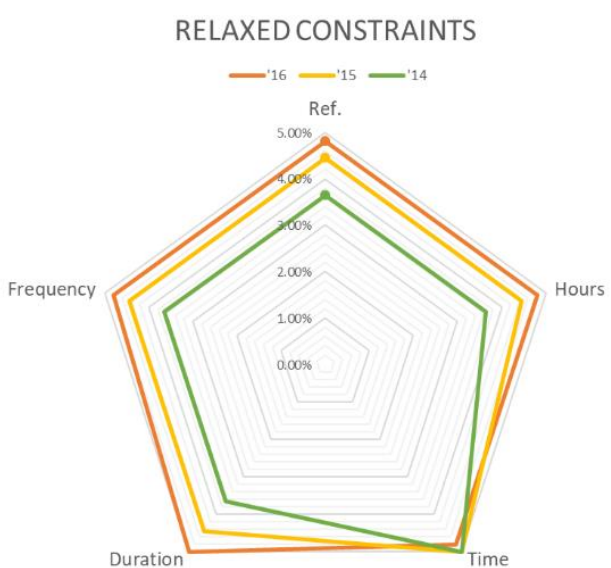

(b)

Figure 1. Average contribution in initial sensitivity simulation: (a) With strengthened constraints; (b) With relaxed constraints.

After that, adjustment ranges are set for each operational constraint and repeat the simulation by incrementing the level until meaningful results are observed. The detailed sensitivity analysis results for each constraint are presented next.

\subsection{Impact Analysis}

As mentioned in the previous section, the policy constraints that determine the annual peak demand are defined as four variables, and each policy variable has a different extent of influence on the annual peak demand decisions. Therefore, in this section, adjustment ranges are set according to the characteristics of each policy variable and simulate for every case where a significant change is observed. In addition, simulation results are analyzed, critical variables that exert the greatest influence on peak reduction are identified, and ways to increase this effect are sought. 


\subsubsection{Maximum Dispatch Duration (Hours)}

Under current regulations, the time allotted to each DR resource for taking part in DR events is limited to $60 \mathrm{~h}$ per year. To quantify the change in the annual peak reduction effect caused by adjusting the policy variables, simulate is conducted for the effects of different limits by changing the limit from 20 to $90 \mathrm{~h}$ in units of $10 \mathrm{~h}$.

Simulation results show that reducing or increasing the maximum time for participating in DR events does not affect peak reduction; other variables are more significant determinants. However, reducing the annual duration time more severely lessens the peak reduction effect. At this time, all available DR resources are used in peak reduction, but the peak reduction effect is only slightly reduced compared to the reference case. The simulation results of the sensitivity analysis varying the maximum dispatch duration are summarized in Table 7 . Also, the result of the average contribution and the variation of contribution and reduction are graphically shown in Figure 2.

Table 7. Summary of sensitivity simulation results with maximum dispatch duration.

\begin{tabular}{|c|c|c|c|c|c|c|c|c|c|}
\hline \multirow{2}{*}{$\begin{array}{l}\text { Variable Condition } \\
\text { LDC Pattern }\end{array}$} & \multicolumn{3}{|c|}{$20 \mathrm{~h}$} & \multicolumn{3}{|c|}{$30 \mathrm{~h}$} & \multicolumn{3}{|c|}{$40 / 50 / 70 / 80 / 90 \mathrm{~h}$} \\
\hline & $` 16$ & $’ 15$ & $` 14$ & ‘ 16 & $' 15$ & $‘ 14$ & $' 16$ & $' 15$ & $' 14$ \\
\hline Average Contribution (\%) & 4.05 & 4.45 & 3.65 & 4.74 & 4.45 & 3.65 & 4.80 & 4.45 & 3.65 \\
\hline Contribution Variation (\%) & -0.75 & 0.00 & 0.00 & -0.06 & 0.00 & 0.00 & 0.00 & 0.00 & 0.00 \\
\hline Reduction Variation (\%) & -15.59 & 0.00 & 0.00 & -1.33 & 0.00 & 0.00 & 0.00 & 0.00 & 0.00 \\
\hline Peak Determinants & Exh. & $\mathrm{T}$ & $\mathrm{T}$ & Exh & $\mathrm{T}$ & $\mathrm{T}$ & $\mathrm{D} / \mathrm{F}$ & $\mathrm{T}$ & $\mathrm{T}$ \\
\hline
\end{tabular}

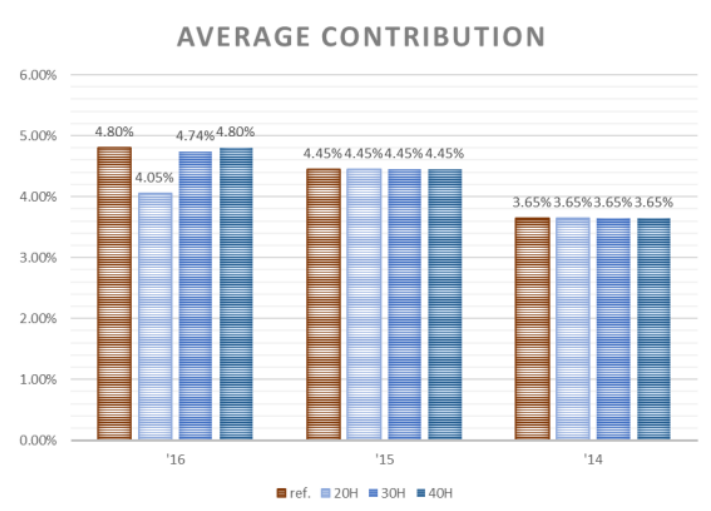

(a)

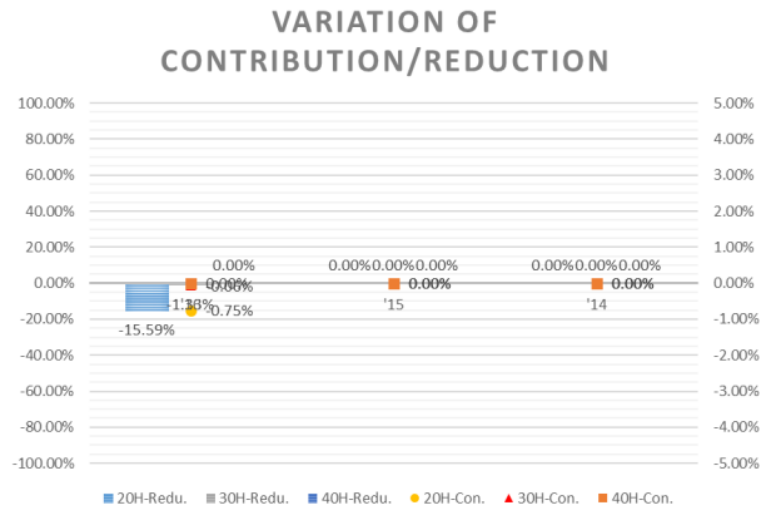

(b)

Figure 2. Sensitivity simulation results of maximum dispatch duration constraint: (a) Average contribution; (b) Variation of contribution and reduction.

\subsubsection{Dispatchable Time (Time)}

In the initial sensitivity analysis, only the available time period for participation is altered, without changing the total time available for DR events. In this sensitivity analysis, both the changeable time slot and the entire available time range are widened and narrowed.

According to the simulation results, the rate of change is larger than the other three policy variables in most cases. As expected, when the time period of the DR event is changed to include more time periods and the time period is moved to around the reference case time, the peak reduction effect is increased. In some cases, the annual peak demand could be reduced by a maximum amount.

However, when the width of the DR event time zone is reduced and the time slot is also partially excluded, the peak reduction effect is significantly reduced through almost the entire demand pattern. Even if the width is extremely small, there may be no peak reduction effect at all. The simulation results for the sensitivity analysis varying dispatchable time are summarized in Table 8. Figure 3 graphically shows the result of the average contribution and the variation of contribution and reduction. 
Table 8. Summary of sensitivity simulation results with dispatchable Time.

\begin{tabular}{|c|c|c|c|c|c|c|c|c|c|c|c|c|}
\hline \multirow{2}{*}{$\begin{array}{c}\text { Variable Condition } \\
\text { LDC pattern }\end{array}$} & \multicolumn{3}{|c|}{$08-21$} & \multicolumn{3}{|c|}{$07-22$} & \multicolumn{3}{|c|}{ 10-19 } & \multicolumn{3}{|c|}{ 11-18 } \\
\hline & '16 & '15 & '14 & '16 & ‘15 & '14 & ‘16 & ‘15 & ‘14 & '16 & ‘15 & ‘14 \\
\hline Average Contribution (\%) & 4.80 & 5.00 & 5.00 & 4.80 & 5.00 & 5.00 & 3.64 & 0.48 & 0.54 & 2.16 & 0.00 & 0.00 \\
\hline Contribution Variation (\%) & 0.00 & 0.56 & 1.36 & 0.00 & 0.56 & 1.36 & -1.16 & -3.96 & -3.11 & -2.64 & -4.45 & -3.65 \\
\hline Reduction Variation (\%) & 0.00 & 12.50 & 37.21 & 0.00 & 12.50 & 37.21 & -24.11 & -89.12 & -85.25 & -54.99 & -100 & -100 \\
\hline Peak Determinants & $\mathrm{D} / \mathrm{F}$ & $\operatorname{Max}$ & $\operatorname{Max}$ & $\mathrm{D} / \mathrm{F}$ & $\operatorname{Max}$ & $\operatorname{Max}$ & $\mathrm{T}$ & $\mathrm{T}$ & $\mathrm{T}$ & $\mathrm{T}$ & $\mathrm{T}$ & $\mathrm{T}$ \\
\hline
\end{tabular}

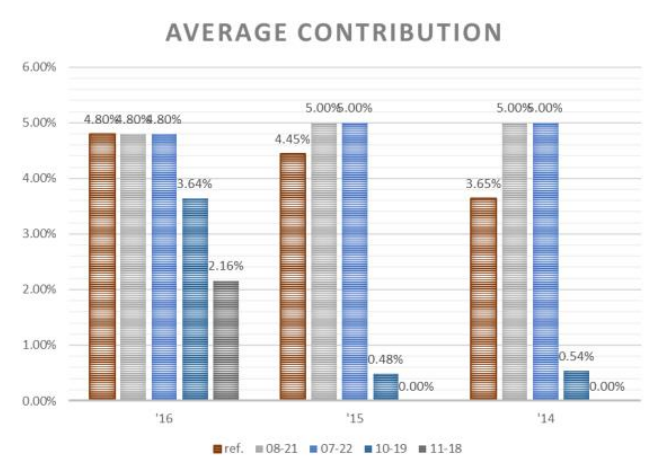

(a)

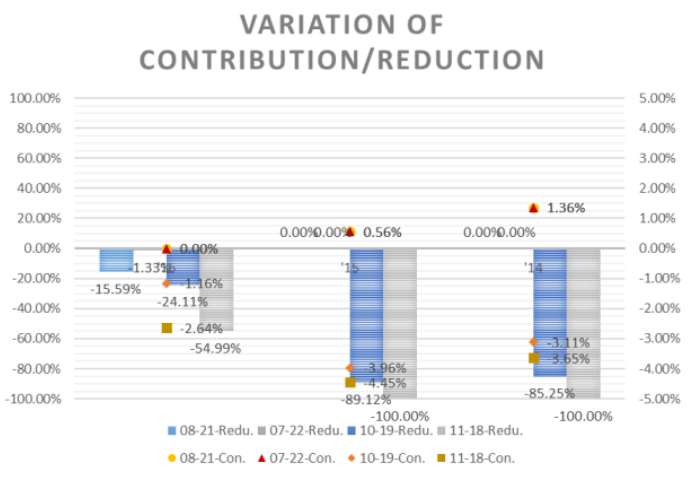

(b)

Figure 3. Sensitivity simulation results of dispatchable Time constraint: (a) Average contribution; (b) Variation of contribution and reduction.

\subsubsection{Sustained Response Period (Duration)}

Once the DR event starts, the maximum duration to sustain demand reduction is set to 2,3 , 5 , and $6 \mathrm{~h}$ (recall the reference case of $4 \mathrm{~h}$ ). According to the results of the simulation, increasing the duration of demand reduction does not greatly improve the peak reduction effect. However, reducing the participation time of the duration constraint significantly reduced the peak reduction effect in all cases, and the factors determining the annual peak demand in all cases was the duration and the frequency constraint.

For example, in the case of the electricity demand pattern in 2016, if the duration of demand reduction for each DR resource is a maximum of $2 \mathrm{~h}$, overall peak reduction effect has decreased by about 2.21 percentage points from $4.80 \%$ to $2.59 \%$. This is a decrease of more than $46 \%$ from the reference case demand reduction capacity. The equivalent capacity is about 1916 MWh or more, or two nuclear power plants. The simulation results for the sensitivity analysis varying the sustained response period are summarized in Table 9. Also, the result of the average contribution and the variation of contribution and reduction are graphically shown in Figure 4.

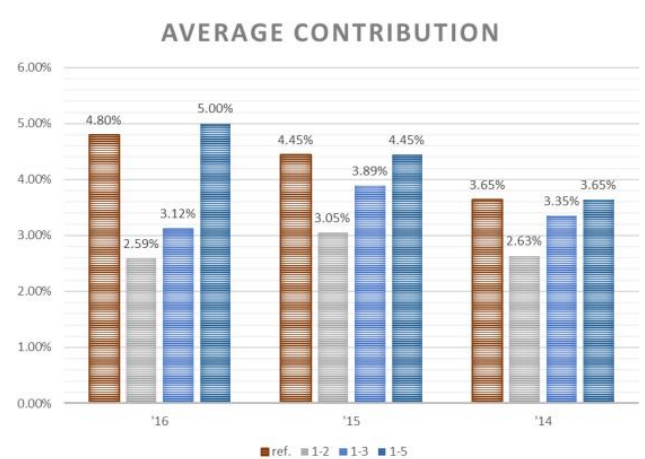

(a)

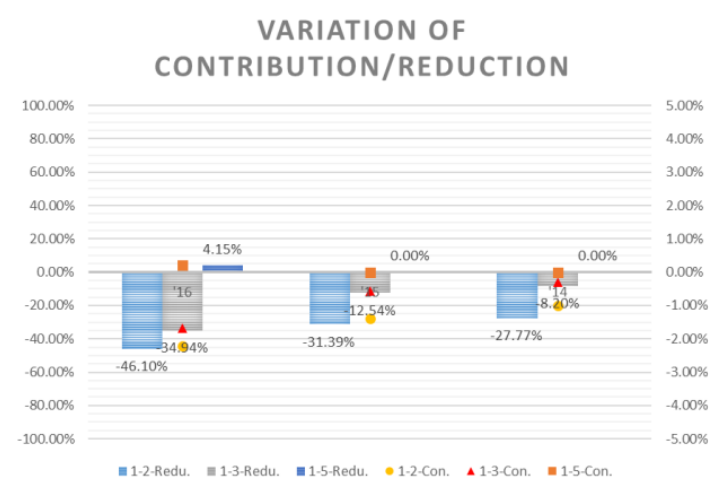

(b)

Figure 4. Sensitivity simulation results of sustained response period constraint: (a) Average contribution; (b) Variation of contribution and reduction. 
Table 9. Summary of sensitivity simulation results with sustained response period.

\begin{tabular}{|c|c|c|c|c|c|c|c|c|c|}
\hline \multirow{2}{*}{$\begin{array}{l}\text { Variable Condition } \\
\text { LDC pattern }\end{array}$} & \multicolumn{3}{|c|}{$1-2$} & \multicolumn{3}{|c|}{$1-3$} & \multicolumn{3}{|c|}{$1-5 / 1-6$} \\
\hline & ‘6 & ‘15 & $` 14$ & ‘16 & ‘15 & ‘14 & ‘16 & ‘15 & ‘14 \\
\hline Average Contribution (\%) & 2.59 & 3.05 & 2.63 & 3.12 & 3.89 & 3.35 & 5.00 & 4.45 & 3.65 \\
\hline Contribution Variation (\%) & -2.21 & -1.40 & -1.01 & -1.68 & -0.56 & -0.30 & 0.20 & 0.00 & 0.00 \\
\hline Reduction Variation (\%) & -46.10 & -31.39 & -27.77 & -34.94 & -12.54 & -8.20 & 4.00 & 0.00 & 0.00 \\
\hline Peak Determinants & $\mathrm{D} / \mathrm{F}$ & $\mathrm{D} / \mathrm{F}$ & $\mathrm{D} / \mathrm{F}$ & $\mathrm{D} / \mathrm{F}$ & $\mathrm{D} / \mathrm{F}$ & $\mathrm{D} / \mathrm{F}$ & $\mathrm{D} / \mathrm{F}$ & $\mathrm{T}$ & $\mathrm{T}$ \\
\hline
\end{tabular}

\subsubsection{Available Number of Dispatches (Frequency)}

Currently, each DR resource can participate in an event up to twice a day. The sensitivity simulation is conducted for each of two possible cases.

Simulation results show that increasing the number of events that a DR resource can participate in during a day has little effect on the peak reduction effect. On the other hand, limiting the possibility of event participation to once a day significantly reduces the peak reduction effect compared to the reference case. The results for sensitivity analysis varying the number of dispatches per day are summarized in Table 10. Figure 5 below graphically shows the result of the average contribution and the variation of contribution and reduction.

Table 10. Summary of sensitivity simulation results with the allowed number of dispatches per day.

\begin{tabular}{lcccccc}
\hline Variable Condition & \multicolumn{3}{c}{ 1/day } & \multicolumn{3}{c}{ 3/day } \\
\hline LDC pattern & $' 16$ & $' 15$ & $' 14$ & $' 16$ & $' 15$ & $' 14$ \\
\hline Average Contribution (\%) & 3.79 & 3.89 & 3.35 & 4.80 & 4.45 & 3.65 \\
Contribution Variation (\%) & -1.02 & -0.56 & -0.30 & 0.00 & 0.00 & 0.00 \\
Reduction Variation (\%) & -21.17 & -12.54 & -8.20 & 0.00 & 0.00 & 0.00 \\
Peak Determinants & $\mathrm{D} / \mathrm{F}$ & $\mathrm{D} / \mathrm{F}$ & $\mathrm{D} / \mathrm{F}$ & $\mathrm{D} / \mathrm{F}$ & $\mathrm{T}$ & $\mathrm{T}$ \\
\hline
\end{tabular}

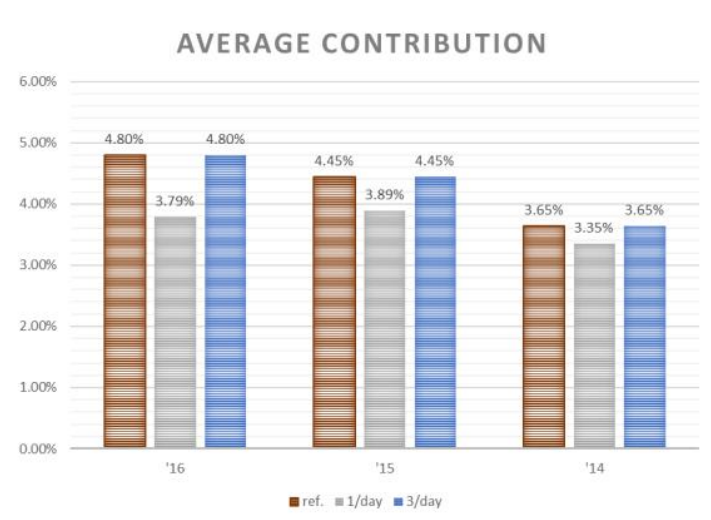

(a)

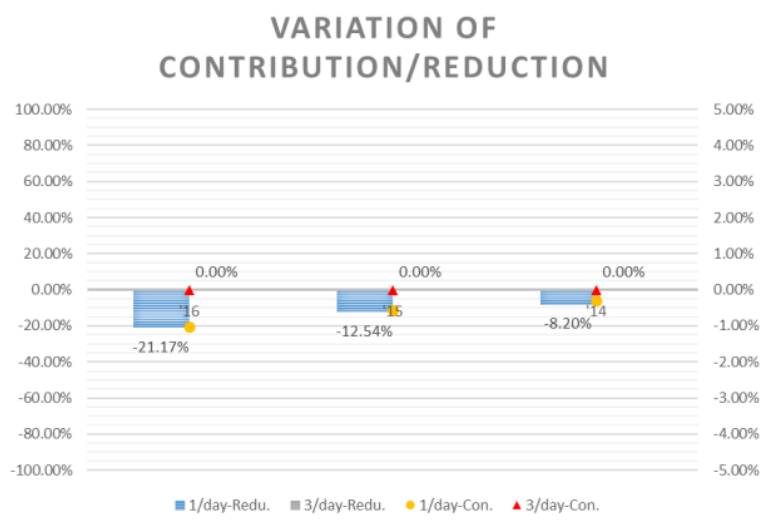

(b)

Figure 5. Sensitivity simulation results of the number of available dispatches constraint: (a) Average contribution; (b) Variation of contribution and reduction.

\section{Discussion}

As DR resources are attracting attention worldwide, the utilization methods of DR resources are diversifying and increasing in variety. This paper focus on the contribution of DR resources to the peak reduction effect and analyze methods to strengthen the effect. It has been four years since the introduction of the Demand Response (DR) market in Korea. The first DR resources installed in 2014 steadily increased from 1520 MW, and as of June 2018, 4151 MW of DR resources have been registered, equivalent to four nuclear power plants [13]. Even though this large and beneficial pool of DR resources have powerful potential, DR resources cannot be efficiently utilized under the current domestic policy system [19]. 
As mentioned in the section describing the simulations performed above, four policy variables that affect the annual peak reduction contribution using DR resources are analyzed. Simulation results estimating the peak reduction contribution based on the current DR market system suggest that DR resources cannot be used at any time as needed, and even if a DR resource is fully utilized, it may not be reflected in the peak reduction contribution. The reason is policy constraints. Therefore, the peak reduction contribution can be improved by slightly revising the DR market policy constraints.

However, since the effectiveness of revising each policy variable has not been verified, the simulation is conducted to increase the peak reduction effect with a sensitivity analysis of each policy variable. Results of the sensitivity analyses indicate that the influence of the four policy variables on the peak reduction contribution by the condition adjustment is very different. In particular, the policy variable that has the most critical impact is the "Dispatchable Time" constraint. If there is a very high demand at a certain time but a DR event cannot be initiated due to current policies, it is a very influential constraint because there is no way to utilize DR resources.

The simulation results confirm that the peak reduction contribution is significantly improved if the DR event is allowed to shift the time period by just one hour, and the contribution of the peak reduction effect is expected to equal the total capacity of registered DR resources. In the meantime, the effects of the other policy variables are not significantly improved upon relaxing the constraint, but the effect is significantly reduced upon the strengthening the constraint.

In this way, even a minor change in a policy constraint can have a great effect. However, it is important to analyze and reflect which constraint can be adjusted effectively and how. A simple benchmarking or trial system change without research can harm participating customers and not improve the effectiveness. Therefore, to implement the appropriate policy system, research should be conducted in many directions. The policy should also take actual customers and market situations into consideration.

\section{Conclusions}

In this article, a new methodology is proposed to estimate the annual peak reduction contribution of DR resources considering various operating constraints of DR resources and characteristics of the power market. Also the peak demand reduction effect is simulated for the domestic power system in Korea from 2017 to 2031 and the sensitivity of the peak reduction effect to major policy variables is analyzed. Simulation results show that under the current DR market system, there are some cases in which DR resources cannot be effectively utilized due to policy constraints. In particular, the policy variable that has the most critical impact on the demand reduction contribution is the "Dispatchable Time" constraint. Thus, a marginal change in this constraint can improve the DR resource contribution. In some cases, annual peak demand could be reduced by the maximum amount of registered DR resource capacity.

Therefore, it is necessary to estimate the peak demand reduction contribution considering the characteristics of DR resources more accurately and to design a policy system for effectively utilizing DR resources in order to efficiently operate the electric power market and establish a long-term resource plan. Although demand forecast is not addressed in this article, because the power demand pattern also has a great influence on the peak reduction effect, it is also necessary to analyze and predict the changing demand patterns and operate the DR resources flexibly. To utilize the potential of DR resources to the maximum extent and to make meaningful institutional improvements in the nation, future research should be actively conducted from various perspectives.

Author Contributions: Conceptualization, S.L. and J.K.; data analysis, simulation, and methodology framework development, S.L. and J.K.; writing, review, and editing, S.L. and J.K. Project management and supervision, J.K.

Funding: This work was supported by the Korea Institute of Energy Technology Evaluation and Planning (KETEP) under the Ministry of Trade, Industry \& Energy (MOTIE) of the Republic of Korea (No. 20181210301380) and by GTI research fund of GIST (GK08810).

Conflicts of Interest: The authors have no conflicts of interest to declare. 


\section{References}

1. Paterakis, N.G.; Erdinç, O.; Catalão, J.P. An overview of demand response: Key-elements and international experience. Renew. Sustain. Energy Rev. 2017, 69, 871-891. [CrossRef]

2. Li, N.; Chen, L.; Low, S.H. Optimal demand response based on utility maximization in power networks. In Proceedings of the 2011 IEEE Power and Energy Society General Meeting, Detroit, MI, USA, 24-29 July 2011; pp. 1-8. [CrossRef]

3. Palensky, P.; Dietrich, D. Demand side management: Demand response, intelligent energy systems, and smart loads. IEEE Trans. Ind. Inform. 2011, 7, 381-388. [CrossRef]

4. Jung, Y. Analysis of Participation Effectiveness of Demand Response Resource. Electric Power Market; Korea Energy Economics Institute: Seongan-dong, Korea, 2016.

5. Selvakumar, K.; Vijayakumar, K.; Boopathi, C. Demand response unit commitment problem solution for maximizing generating companies' profit. Energies 2017, 10, 1465. [CrossRef]

6. Satchwell, A.; Hledik, R. Analytical frameworks to incorporate demand response in long-term resource planning. Util. Policy 2014, 28, 73-81. [CrossRef]

7. Wang, J.; Liu, C.; Ton, D.; Zhou, Y.; Kim, J.; Vyas, A. Impact of plug-in hybrid electric vehicles on power systems with demand response and wind power. Energy Policy 2011, 39, 4016-4021. [CrossRef]

8. Molina-Garcia, A.; Kessler, M.; Fuentes, J.A.; Gomez-Lazaro, E. Probabilistic characterization of thermostatically controlled loads to model the impact of demand response programs. IEEE Trans. Power Syst. 2011, 26, 241-251. [CrossRef]

9. Aalami, H.; Moghaddam, M.P.; Yousefi, G. Demand response modeling considering interruptible/curtailable loads and capacity market programs. Appl. Energy 2010, 87, 243-250. [CrossRef]

10. Shao, S.; Pipattanasomporn, M.; Rahman, S. Grid integration of electric vehicles and demand response with customer choice. IEEE Trans. Smart Grid 2012, 3, 543-550. [CrossRef]

11. Dietrich, K.; Latorre, J.M.; Olmos, L.; Ramos, A. Demand response in an isolated system with high wind integration. IEEE Trans. Power Syst. 2012, 27, 20-29. [CrossRef]

12. Taqqali, W.M.; Abdulaziz, N. Smart grid and demand response technology. In Proceedings of the IEEE International Energy Conference and Exhibition, EnergyCon 2010, Portland, OR, USA, 18-22 December 2010; pp. 710-715. [CrossRef]

13. Demand Response Market Operation Status and Implications. Available online: http://www.energy.or.kr/ web/kem_home_new/energy_issue/mail_vol92/pdf/issue_195_01_01.pdf (accessed on 15 October 2018).

14. Joung, M.; Kim, J. Assessing demand response and smart metering impacts on long-term electricity market prices and system reliability. Appl. Energy 2013, 101, 441-448. [CrossRef]

15. Torriti, J.; Hassan, M.G.; Leach, M. Demand response experience in Europe: Policies, programmes and implementation. Energy 2010, 35, 1575-1583. [CrossRef]

16. Walawalkar, R.; Fernands, S.; Thakur, N.; Chevva, K.R. Evolution and current status of demand response (DR) in electricity markets: Insights from PJM and NYISO. Energy 2010, 35, 1553-1560. [CrossRef]

17. Bradley, P.; Leach, M.; Torriti, J. A review of the costs and benefits of demand response for electricity in the UK. Energy Pol. 2013, 52, 312-327. [CrossRef]

18. Act, E.P. Energy policy act of 2005, US Congress. 2005.

19. Pinson, P.; Madsen, H. Benefits and challenges of electrical demand response: A critical review. Renew. Sustain. Energy Rev. 2014, 39, 686-699. [CrossRef]

20. Strbac, G. Demand side management: Benefits and challenges. Energy Pol. 2008, 36, 4419-4426. [CrossRef]

21. Nolan, S.; O'Malley, M. Challenges and barriers to demand response deployment and evaluation. Appl. Energy 2015, 152, 1-10. [CrossRef]

22. Cappers, P.; Goldman, C.; Kathan, D. Demand response in US electricity markets: Empirical evidence. Energy 2010, 35, 1526-1535. [CrossRef]

23. Kim, J.H.; Shcherbakova, A. Common failures of demand response. Energy 2011, 36, 873-880. [CrossRef]

24. Stoll, B.; Buechler, E.; Hale, E. The value of demand response in Florida. Electr. J. 2017, 30, 57-64. [CrossRef]

25. Kwag, H.G.; Kim, J.O. Optimal combined scheduling of generation and demand response with demand resource constraints. Appl. Energy 2012, 96, 161-170. [CrossRef]

26. Zhou, Y.; Mancarella, P.; Mutale, J. Modelling and assessment of the contribution of demand response and electrical energy storage to adequacy of supply. Sustain. Energy Grids Netw. 2015, 3, 12-23. [CrossRef] 
27. Keane, A.; Tuohy, A.; Meibom, P.; Denny, E.; Flynn, D.; Mullane, A.; O’Malley, M. Demand side resource operation on the Irish power system with high wind power penetration. Energy Pol. 2011, 39, 2925-2934. [CrossRef]

28. GAMS. Available online: https://www.gams.com/. (accessed on 23 October 2018).

29. The 8th Basic Plan for Long-term Electricity Supply and Demand (BPE); Ministry of Trade, Industry and Energy: Se-jong, Korea, 2017. 